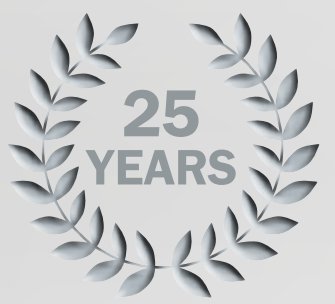

\title{
Promoting excellence in care: 25 years at the heart of nursing
}

\author{
Alan Glasper
}

Emeritus Professor, University of Southampton, discusses the contribution of the British Journal of Nursing to enhancing contemporary nursing within the health service over the past quarter of a century

I n April 1992 the Royal College of Nursing (RCN) held its annual congress at the Winter Gardens in Blackpool, Lancashire. One of the many important topics discussed that year was the policy and practice implications that might arise if nurses refused to care for certain patients or if patients refused to be cared for by a particular nurse. This was because it was an era of health care that was challenged by HIV and AIDS, which had provoked moral outrage and significant levels of social prejudice (Boyd, 1992).

As with all RCN congresses, the days and evenings were filled with main hall debates and individual fringe meetings where various topics pertinent to nurses and nursing were discussed.This was the second RCN congress I had attended in my capacity as the vice chair of the RCN's Society of Paediatric Nursing. The previous year I had been appointed as the foundation professor of nursing studies at the University of Southampton, the first practising children's nurse to be awarded a professional chair and, it is interesting to note, one of only nine university professors of nursing in post at that time in the UK. Today there are hundreds of nursing professors in the UK, a sign of the profession's maturity.

It is important to remember that, in 1992, the vast majority of initial nurse training courses were studied at diploma level in NHS colleges of nursing as a result of Project 2000 , which had commenced in 1990. Thus at that particular RCN congress in Blackpool in 1992, members were still reflecting on these new changes to the educational preparation of nurses and other topics such as the impact of clinical grading, which had been introduced in 1988. Because of this there were many fringe meetings to attend where these aspects were being discussed.

\section{A new nursing journal}

One afternoon, on my way to participate in one of these fringe meetings, I bumped into Mark Allen, who I knew as the publisher of the monthly journal Nursing. Mark told me that he was hosting an impromptu meeting later that day to discuss the launch of a new nursing journal and wondered if I would like to come along. I did and it was at this meeting that I learned of the demise of the journal Nursing and its replacement, like a phoenix rising from the ashes of the old, with a new journal to be named the British Journal of Nursing (BJN).

Mark Allen believed that the

\section{The $B J N$ would} give the nursing community

access to patientfocused research and innovation in clinical practice 9

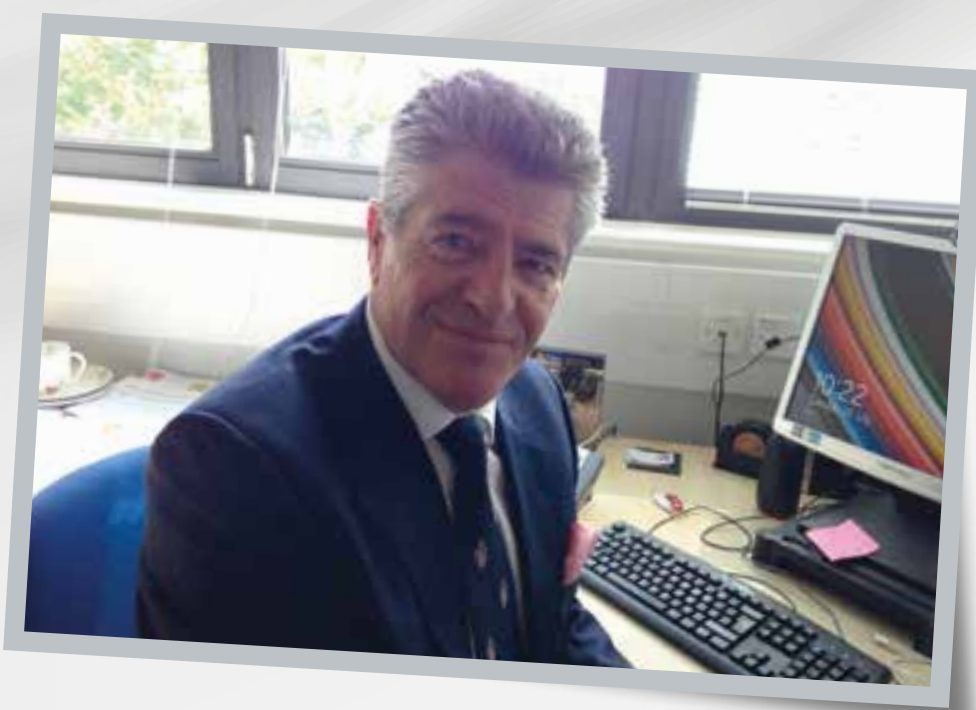

monthly publication was no longer fit for purpose in that it was failing to address the profound and contemporary issues in the profession and health service at a time when nursing was increasingly providing leadership to a beleaguered NHS that was trying to come to terms with major demographic and morbidity changes such as the challenge of elderly care.

Mark's vision was to produce a new nursing journal that would command the same respect that the British Medical Journal (BMJ) did to the medical profession. Mark's initial cover design in many ways reflected that of the $B M J$ and he passionately wanted his new journal to provide gravitas to add to the growing professionalism of nursing and not to be seen as simply a magazine for nurses to skim through during their coffee break. To achieve this, Mark set out to appoint an editorial board that would represent all members of the profession. Hence he engaged senior clinicians and academics from all fields of practice, including myself as a children's nurse. Uniquely, Mark announced that the new journal would be published fortnightly, with 22 issues per year and with peer-reviewed content that would give the nursing community access to patientfocused research and innovation in clinical practice presented in an easy-to-read, accessible style that would provide answers to those issues affecting daily practice. Crucially, Mark was aware that his new journal was the British Journal of Nursing and not simply of nurses; in other words, he was conscious then of the need to engage with all staff who provided nursing care, not just nurses, perhaps made more meaningful today with the emergence of the nursing associate.

Over the past 25 years the BJN has endeavoured to provide the evidence base for practice with the aim of directly influencing the 
delivery of optimum patient care and enhancing clinical outcomes. Much has happened to the nursing profession over the past 25 years but not least the rapid emergence of nursing as an all-graduate profession between the years 2011 and 2013. To provide some historical context, the University of Edinburgh had been the first UK higher education institution to offer a pre-registration bachelor's degree in nursing, in 1960, with the University of Wales, Cardiff, introducing its own nursing degree in 1972 (Bircumshaw and Chapman 1988), followed by the University of Manchester in 1974. In 1976 the University of Ulster commenced undergraduate nursing for Northern Ireland and subsequently a number of English universities introduced nursing degrees during the 1980s (Carpenter et al, 2013).

The introduction of a better educated workforce demanded enhanced nursing journals and the responsiveness of the BJN in giving these nurses access to research-based but clinically relevant literature that had a direct bearing on patient care has been pivotal throughout the 25 years since its inauguration.

\section{Historical roots}

The origins of the current regulator for nurses, the Nursing and Midwifery Council (NMC), lies in the campaign by 19 th century Victorian nurses for better public recognition of their profession.
Doctors had been regulated under the auspices of the Medical Act since 1858 and Baly (2002) discusses the contribution of Ethel Bedford Fenwick (née Manson), who led the nurse registration movement in the 1880s. Mrs Fenwick had initially trained as a children's nurse probationer at the Nottingham Children's Hospital before undertaking general nursing in Manchester (Glasper and Charles Edwards, 2002). She was an intelligent and ambitious woman who was very politically aware, becoming a sister at the London Hospital at only 24 years of age.

Mrs Fenwick founded the British Nursing Association in 1887 to promote her aspirations for nurse registration and later acquired an early nursing journal entitled The Nursing Record in 1888, where she used her position as editor in chief to campaign and lobby for an act of parliament to establish a nursing register. In 1902 she changed the name of the journal to the British Journal of Nursing (Lorentzon, 2004).

She continued to use the BJN to promote the notion of a registered nurse, although a contemporary of hers, Florence Nightingale, was actually opposed to nurse registration. Her efforts were eventually rewarded after many years of campaigning through, among others, the good offices of the BJN when, in December 1919, the Nurses' Bill received royal assent with a mandate to create a General

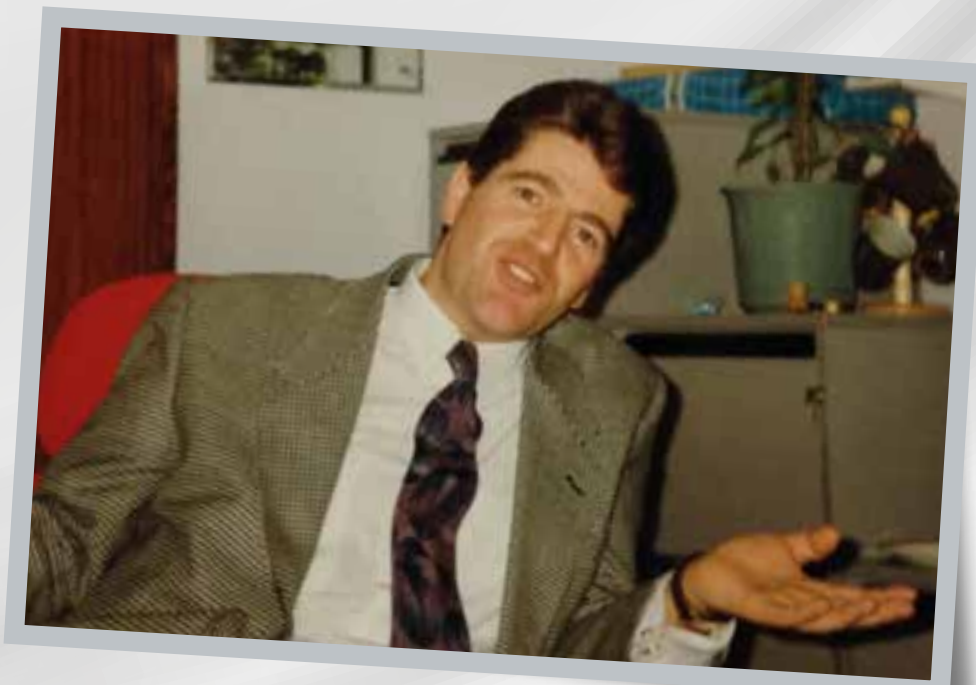

Nursing Council (GNC) for England and Wales, for Scotland and for Ireland. Ethel Bedford Fenwick, who was the first registered nurse of the UK (GNC nurse number 1) continued as the editor in chief of the BJN for many years. Although she died in March 1947, the journal continued to be published until its demise in 1956.

\section{A contemporary voice}

When Mark Allen resurrected the $B J N$ in 1992, he foresaw that the nursing profession and, in particular, nurse education, would undergo radical change. During the past 25 years, his journal has endeavoured to be at the forefront of those changes. Like the BJN of the early 20th century the contemporary $B J N$ will continue to be the voice of British nursing for many years to come. BJN

\section{Alan Glasper in the early} 1990s

Baly ME. Nursing and social change. 3rd edn. Abingdon: Taylor and Francis; 2002

Bircumshaw D, Chapman CM. A followup of the graduates of the 3-year post-registration Bachelor of Nursing degree course in the University of Wales. J Adv Nurs. 1988; 13(4):520524

Boyd KM. HIV infection and AIDS: the ethics of medical confidentiality. J Med Ethics. 1992; 18(4):173-179

Carpenter D, Glasper A, Jowett R, Nicholls P. Celebrating 30 years of nursing at the University of Southampton. Br J Nurs. 2013; 22(15):889-892. https:// doi.org/10.12968/bjon.2013.22.15.889

Glasper EA, Charles-Edwards I. The child first and always: the registered children's nurse over 150 years. Part one. Paediatr Nurs. 2002; 14(4):38-42. https://doi. org/10.7748/paed2002.05.14.4.38 c799 Journal of Nursing archives, 1888 1956. Br J Nurs. 2004; 13(5):280284. https://doi.org/10.12968/ bjon.2004.13.5.12411
Lorentzon M. Nursing Record/British

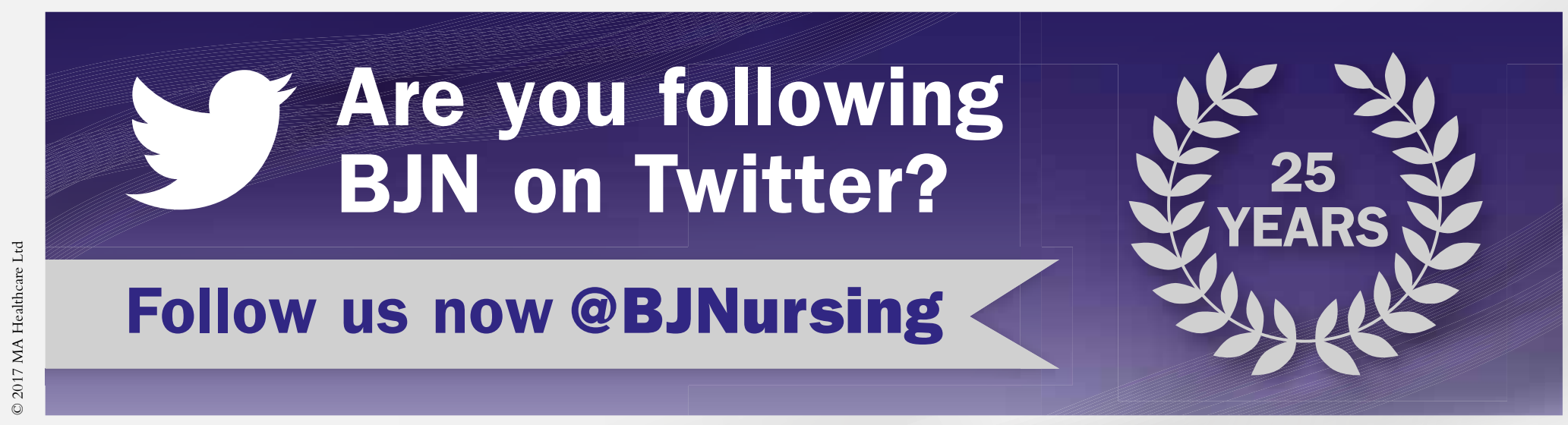

